\title{
Temporal variation in ${ }^{129} I$ and ${ }^{127} I$ in aerosols from Xi'an, China: influence of East Asian monsoon and heavy haze events
}

\author{
Luyuan Zhang ${ }^{1,2,5}$, Xiaolin Hou ${ }^{1,2,3,5}$, Sheng $\mathrm{Xu}^{4}$, Tian Feng ${ }^{1}$, Peng Cheng ${ }^{1}$, Yunchong $\mathrm{Fu}^{1}$, and Ning Chen ${ }^{1}$ \\ ${ }^{1}$ State Key Laboratory of Loess and Quaternary Geology, Shaanxi Key Laboratory of Accelerator Mass Spectrometry \\ Technology and Application, Xi' an AMS Center, Institute of Earth Environment CAS, Xi' an 710061, China \\ ${ }^{2}$ Center for Excellence in Quaternary Science and Global Change, Chinese Academy of Sciences, Xi' an 710061, China \\ ${ }^{3}$ Center for Nuclear Technologies, Technical University of Denmark, Ris $\varnothing$ Campus, Roskilde 4000, Denmark \\ ${ }^{4}$ Institute of Surface-Earth System Science, Tianjin University, Tianjin 300072, China \\ ${ }^{5}$ Open Studio for Oceanic-Continental Climate and Environment Changes, Pilot National Laboratory for Marine Science \\ and Technology (Qingdao), Qingdao 266061, China
}

Correspondence: Luyuan Zhang (zhangluyuan.118@163.com, zhangly@ieecas.cn)

Received: 12 September 2019 - Discussion started: 20 September 2019

Revised: 23 January 2020 - Accepted: 27 January 2020 - Published: 3 March 2020

\begin{abstract}
Aerosol iodine isotopes are pivotal links in atmospheric circulation of iodine in both atmospheric and nuclear sciences, while their sources, temporal change and transport mechanism are still not well understood. This work presents the day-resolution temporal variation in iodine-129 $\left({ }^{129} \mathrm{I}\right)$ and iodine-127 ( $\left.{ }^{127} \mathrm{I}\right)$ concentrations in aerosols from Xi' an, north-west China, during 2017/18. Both iodine isotopes have significant fluctuations with time, showing the highest levels in winter, approximately 2-3 times higher than in other seasons, but the correlation between ${ }^{129} \mathrm{I}$ and ${ }^{127} \mathrm{I}$ concentrations reflects that they have different sources. Aerosol ${ }^{127} \mathrm{I}$ concentrations are found to be noticeably positively correlated with air quality index and five air pollutants. Enhanced fossil fuel combustion and inverse weather conditions can explain the increased concentrations and peaks of ${ }^{127} \mathrm{I}$ in winter. The change in ${ }^{129}$ I concentrations confirms that the source and level of ${ }^{129} \mathrm{I}$ in the monsoonal region were alternatively dominated by the ${ }^{129} \mathrm{I}$-enriched East Asian winter monsoon and the ${ }^{129} \mathrm{I}$-poor East Asian summer monsoon. The mean ${ }^{129} \mathrm{I} /{ }^{127}$ I number ratio of $(92.7 \pm 124) \times 10^{-10}$ provides an atmospheric background level for the purpose of nuclear environmental safety monitoring. This study suggests that locally discharged stable ${ }^{127} \mathrm{I}$ and externally input ${ }^{129} \mathrm{I}$ are likely involved in fine particles formation in urban air, which provides insights into the long-range transport of air pollutants and iodine's role in particulate formation in urban atmosphere.
\end{abstract}

\section{Introduction}

Iodine is one of the active halogen elements and is involved in plenty of atmospheric chemical reactions (i.e. ozone depletion and new particle formation from condensable iodinecontaining vapours), drawing increasing attention in not only atmospheric science but also environmental fields in recent years (Saiz-Lopez et al., 2012). A number of studies on atmospheric iodine just focus on the processes and mechanisms in marine boundary layer since over $99.8 \%$ of iodine is derived from ocean (McFiggans et al., 2000). Other sources of iodine in air are comprised of volatile iodine and resuspended particles from soil, as well as combustion of fossil fuel (Fuge and Johnson, 1986). Whitehead (1984) estimated annual release of iodine from fossil fuel combustion is about $400 \mathrm{t}$, accounting for only $0.1 \%$ of total iodine in air. In contrast, anthropogenic iodine in Chinese megacities is believed to be significantly underestimated due to coal combustion (Wu et al., 2014). A few studies have shown high iodine concentrations in air and particles in China (Gao et al., 2010; Xu et al., 2010). Although marine atmospheric iodine has been proven to form fine particles, little is known about terrestrial atmospheric iodine, particularly in urban sites with severe air pollution.

Along with atmospheric circulation of stable ${ }^{127} \mathrm{I}$, longlived radioactive ${ }^{129}$ I with a half-life of 15.7 million years is also of importance to global transport since it is a major 
fission product with a yield of $0.7 \%$ from nuclear industry. China is in a transition phase of energy structure in order to solve environmental pollution issues and has put great emphasis on developing nuclear power (World Nuclear Association, 2017). Nuclear waste reprocessing is also in the process of construction in China, which may be a key source of ${ }^{129} \mathrm{I}$ in the future. Investigation of the level, sources and temporal changes is extremely necessary for nuclear environmental safety assessment and nuclear emergency preparedness. Environmental ${ }^{129} \mathrm{I} /{ }^{127} \mathrm{I}$ number ratios have been increased from the natural ${ }^{129} \mathrm{I}$ level of $10^{-12}$ to an anthropogenic level beyond $10^{-10}$ in the modern environment due to atmospheric nuclear weapon testing, nuclear accidents, nuclear fuel reprocessing process, etc (Snyder et al., 2010). More than $95 \%$ of the environmental ${ }^{129} \mathrm{I}$ was discharged by the two European nuclear fuel reprocessing plants (NFRPs), Sellafield in United Kingdom and La Hague in France, to the seas and air in liquid and gaseous forms, respectively. As a consequence of ${ }^{129}$ I releases from NFRPs, nuclear accidents and nuclear weapon testing sites, the global distribution of ${ }^{129} \mathrm{I}$ is rather uneven (Snyder et al., 2010). Atmospheric ${ }^{129}$ I investigations have been conducted in Europe, Japan, the United States and Canada, but aerosol ${ }^{129} \mathrm{I}$ studies are still rare, and no aerosol ${ }^{129} \mathrm{I}$ data are available in China at present (Hasegawa et al., 2017; Hou et al., 2009; Jabbar et al., 2013; Moran et al., 1999; Toyama et al., 2013; Xu et al., 2013). Furthermore, those previous studies present time series of ${ }^{129} \mathrm{I}$ in aerosols in monthly resolution for the purpose of nuclear environmental monitoring. Such a low time resolution is not sufficient to understand the sources, transport and temporal variation pattern and how these factors influence ${ }^{129} \mathrm{I}$.

Here, we present a day-resolution temporal variation in ${ }^{129} \mathrm{I}$ and ${ }^{127} \mathrm{I}$ in aerosols during $2017 / 18$ from a typical monsoonal zone, Xi'an city in the Guanzhong basin of northwest China, to make an attempt to investigate the level, sources and temporal change characteristics of ${ }^{127} \mathrm{I}$ and ${ }^{129} \mathrm{I}$. This study will help to establish a background value of the ${ }^{129} \mathrm{I} /{ }^{127} \mathrm{I}$ number ratio, thereby serving nuclear environmental safety monitoring. The possible factors influencing temporal variation in iodine isotopes are also explored, including meteorological parameters, the East Asian monsoon (EAM) and heavy haze events.

\section{Materials and methods}

The aerosol samples were collected using a high-volume sampler on the roof of Xi' an AMS Center $\left(34^{\circ} 13^{\prime} 25^{\prime \prime} \mathrm{N}\right.$, $109^{\circ} 0^{\prime} 0^{\prime \prime} \mathrm{E}$ ) with an elevation of $440 \mathrm{~m}$ above mean sea level (Fig. 1). Xi' an, located in the Guanzhong basin, is the largest city in north-west China with a population of 9.9 million. The basin is nestled between the Qinling Mountains to the south and the Loess Plateau to the north, and it is a warm temperate zone with semi-humid continental monsoon climate (Fig. 1b).
Sixty-eight aerosol samples were selected for measurement of iodine isotopes using the pyrolysis combined with $\mathrm{AgI}-\mathrm{AgCl}$ co-precipitation for separation. The sample collection and preparation procedure are described in detail in the Supplement (Sect. S1), as previously reported (Zhang et al., 2018b). Accelerator mass spectrometry (AMS; 3MV, High Voltage Engineering Europa B.V., the Netherlands) and inductively coupled plasma mass spectrometry (ICPMS; Agilent 8800, USA) were applied for a determination of ${ }^{129} \mathrm{I} /{ }^{127}$ I number ratios and ${ }^{127} \mathrm{I}$ concentrations, respectively. ${ }^{129} \mathrm{I} /{ }^{127}$ I number ratio of iodine carrier is less than $2 \times 10^{-13}$, and the analytical precisions are within $5 \%$ for all the aerosol samples.

\section{Results}

Results of ${ }^{127} \mathrm{I}$ concentrations, $\gamma\left({ }^{127} \mathrm{I}\right),{ }^{129} \mathrm{I}$ concentrations, $\mathrm{N}\left({ }^{129} \mathrm{I}\right)$, and ${ }^{129} \mathrm{I} /{ }^{127} \mathrm{I}$ number ratios in aerosol samples in Xi'an, China, from March 2017 to March 2018, are shown in Fig. 2. The concentrations of ${ }^{127} \mathrm{I}$ and ${ }^{129} \mathrm{I}$ and the ${ }^{129} \mathrm{I} /{ }^{127} \mathrm{I}$ number ratio fell within $1.21-21.4 \mathrm{ng} \mathrm{m}^{-3},(0.13-$ $7.53) \times 10^{5}$ atoms $\mathrm{m}^{-3}$ and $(10.6-743) \times 10^{-10}$, respectively. The mean values were $6.22 \pm 4.48 \mathrm{ng} \mathrm{m}^{-3},(1.97 \pm 1.65) \times$ $10^{5}$ atoms $\mathrm{m}^{-3}$ and $(92.7 \pm 124) \times 10^{-10}$ for $\gamma\left({ }^{127} \mathrm{I}\right), \mathrm{N}\left({ }^{129} \mathrm{I}\right)$ and the ${ }^{129} \mathrm{I} /{ }^{127} \mathrm{I}$ number ratio, respectively.

${ }^{127} \mathrm{I}$ and ${ }^{129} \mathrm{I}$ in aerosols are characterised with apparent monthly and seasonal variations (Figs. 3 and 4). The minimum and maximum monthly concentrations were observed in August and December for ${ }^{127} \mathrm{I}$ and July and December for ${ }^{129} \mathrm{I}$. The average $\gamma\left({ }^{127} \mathrm{I}\right)$ values in November, December and January $\left(11.4-12.7 \mathrm{ng} \mathrm{m}^{-3}\right)$ were 2 times higher than in other months $\left(3.12-6.70 \mathrm{ng} \mathrm{m}^{-3}\right)$. Distinct from ${ }^{127} \mathrm{I}$, monthly variation in ${ }^{129} \mathrm{I}$ shows the lowest level in June and July, $(0.47-0.50) \times 10^{5}$ atoms $\mathrm{m}^{-3}$, about 2 to 6 times lower than the other months. The maximum ${ }^{129} \mathrm{I} /{ }^{127} \mathrm{I}$ number ratio was not observed in winter months but rather in September.

The average $\gamma\left({ }^{127} \mathrm{I}\right)$ values were $5.68 \pm 2.24,3.61 \pm 1.49$, $6.05 \pm 4.52$ and $10.6 \pm 6.0 \mathrm{ng} \mathrm{m}^{-3}$ in spring, summer, fall and winter, respectively. The level of ${ }^{127} \mathrm{I}$ in winter was about 2 times higher than spring and fall, 3 times higher than summer. $\mathrm{N}\left({ }^{129} \mathrm{I}\right)$ values were $(1.93 \pm 1.90) \times 10^{5},(1.17 \pm 1.55) \times$ $10^{5},(1.92 \pm 1.62) \times 10^{5}$ and $(3.12 \pm 0.72) \times 10^{5}$ atoms m $^{-3}$ in spring, summer, fall and winter, respectively. The level of ${ }^{129} \mathrm{I}$ in winter was about 2 times higher than spring and fall and 3.3 times higher than summer. Seasonal variation in the ${ }^{129} \mathrm{I} /{ }^{127} \mathrm{I}$ number ratio was not so obvious as the concentrations of iodine isotopes. The mean ${ }^{129} \mathrm{I} /{ }^{127} \mathrm{I}$ number ratio of $(119 \pm 185) \times 10^{-10}$ in fall was slightly higher than that of $(82.2 \pm 79.3) \times 10^{-10}$ in spring, $(71.5 \pm 89.3) \times 10^{-10}$ in summer and $(89.3 \pm 70.5) \times 10^{-10}$ in winter. However, the ratios in all four seasons fell in the similar range as that of the whole year.

A weak correlation between ${ }^{129}$ I and ${ }^{127}$ I was found with a Spearman correlation coefficient of $0.33(p<0.01)$ for the 


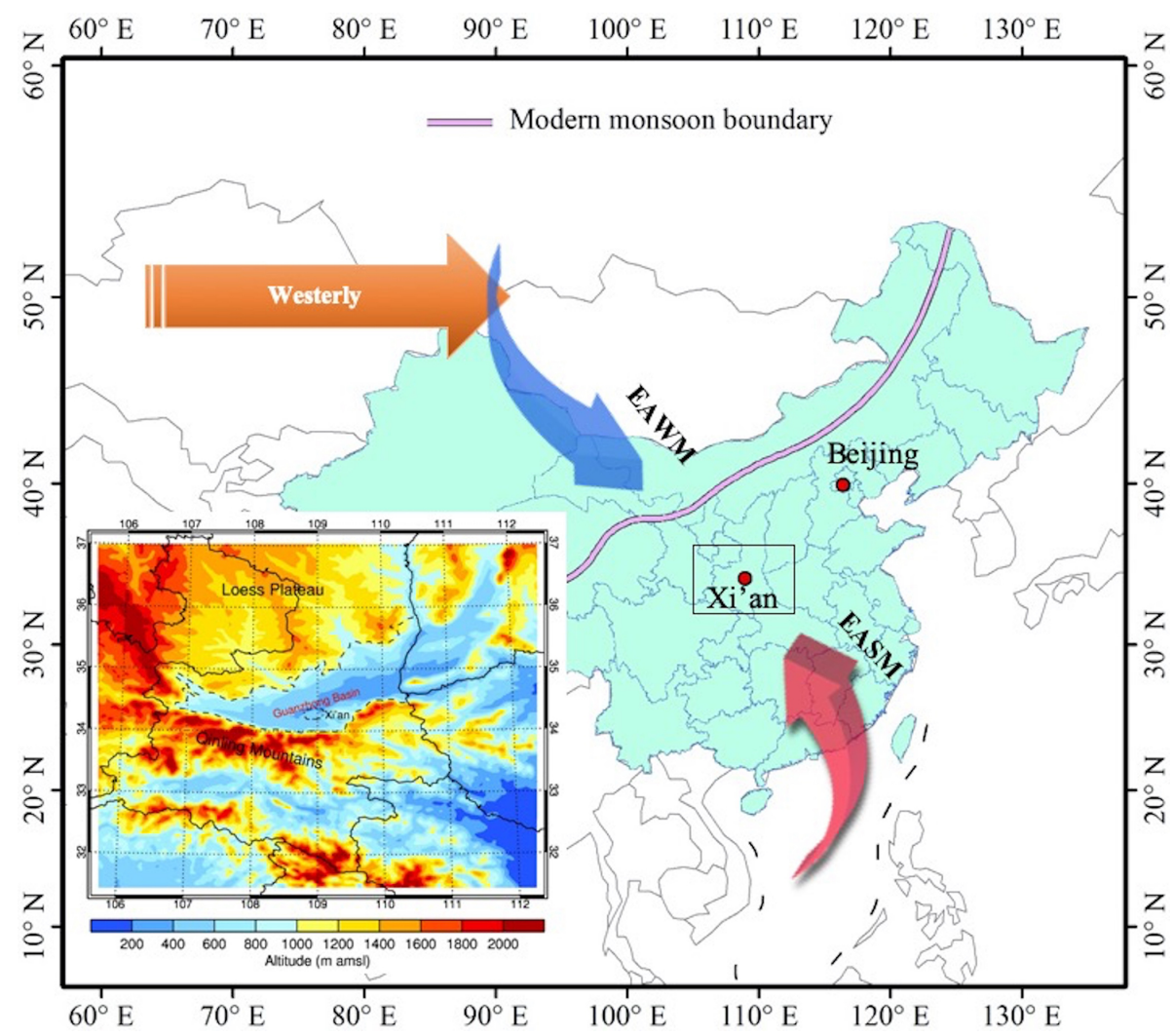

Figure 1. Map showing the sampling location (Xi' an city in rectangle) and East Asian monsoon (EAM) system. The inset shows the topography of the studied area in the Guanzhong basin between the Loess Plateau to the north and Qinling Mountains to the south. East Asian monsoon, constituted by East Asian summer monsoon (EASM) and East Asian winter monsoon (EAWM), is one of vital components of the global atmospheric circulation system. The pink line in the map is the modern monsoon boundary, and the arrows indicate the westerly (orange), the EAWM (blue) and the EASM (red).

whole year data, while no significant correlation was found between the two iodine isotopes in each season at the level of 0.05 (Table 1 and Fig. S1 in the Supplement). The correlation analysis between iodine isotopes and total suspended particle (TSP) indicate that there was a strong correlation between ${ }^{127} \mathrm{I}$ and TSP but no correlation between radioactive ${ }^{129} \mathrm{I}$ and TSP (Fig. S2).

\section{Discussion}

\subsection{Level and sources of ${ }^{127} I$ and ${ }^{129} I$}

The results of a weak correlation in the whole year sampling and no significant correlations in each season between the two isotopes indicate that ${ }^{127} \mathrm{I}$ and ${ }^{129} \mathrm{I}$ have different sources and influence factors.

\subsection{1 $\quad{ }^{127} I$}

The levels of ${ }^{127} \mathrm{I}$ concentrations, particularly in winter, are much higher than those in continental sites (below $0.61 \mathrm{ng} \mathrm{m}^{-3}$ at the South Pole and $2.7-3.3 \mathrm{ng} \mathrm{m}^{-3}$ in
Mpumalanga - previously named the Eastern Transvaal) and comparable to those in coastal and ocean sites (typically below $20 \mathrm{ng} \mathrm{m}^{-3}$ and up to $24 \mathrm{ng} \mathrm{m}^{-3}$ in tropic marine aerosols) (Saiz-Lopez et al., 2012). A similar range of ${ }^{127} \mathrm{I}$ in TSP was observed to be $4.5-22 \mathrm{ng} \mathrm{m}^{-3}$ in a coastal urban area, Shanghai, China, showing the lowest values in summer, and an increase occurred in fall and winter (Gao et al., 2010). Iodine associated with $\mathrm{PM}_{10}$ and $\mathrm{PM}_{2.5}$ (particulate matter with the aerodynamic diameter less than 10 and $2.5 \mu \mathrm{m}$, respectively). was found to be $3-115$ and $4-18 \mathrm{ng} \mathrm{m}^{-3}$, respectively, in urban and island sites of Shanghai, slightly lower than TSP iodine (Cheng et al., 2017; Gao et al., 2010). The marine aerosol iodine offshore China was found to be below $8.6 \mathrm{ng} \mathrm{m}^{-3}$ during the R/V XueLong cruise from July to September 2008 (Xu et al., 2010). The results suggest a relatively high aerosol ${ }^{127} \mathrm{I}$ level in both inland and coastal urban areas in China.

Natural iodine in air is from marine emission through sea spray and gaseous emissions from seas, weathering of base rock and continental release through vegetation and suspended soil particles (Carpenter et al., 2013; Fuge and Johnson, 1986). Due to the influence of south-easterly EASM, 


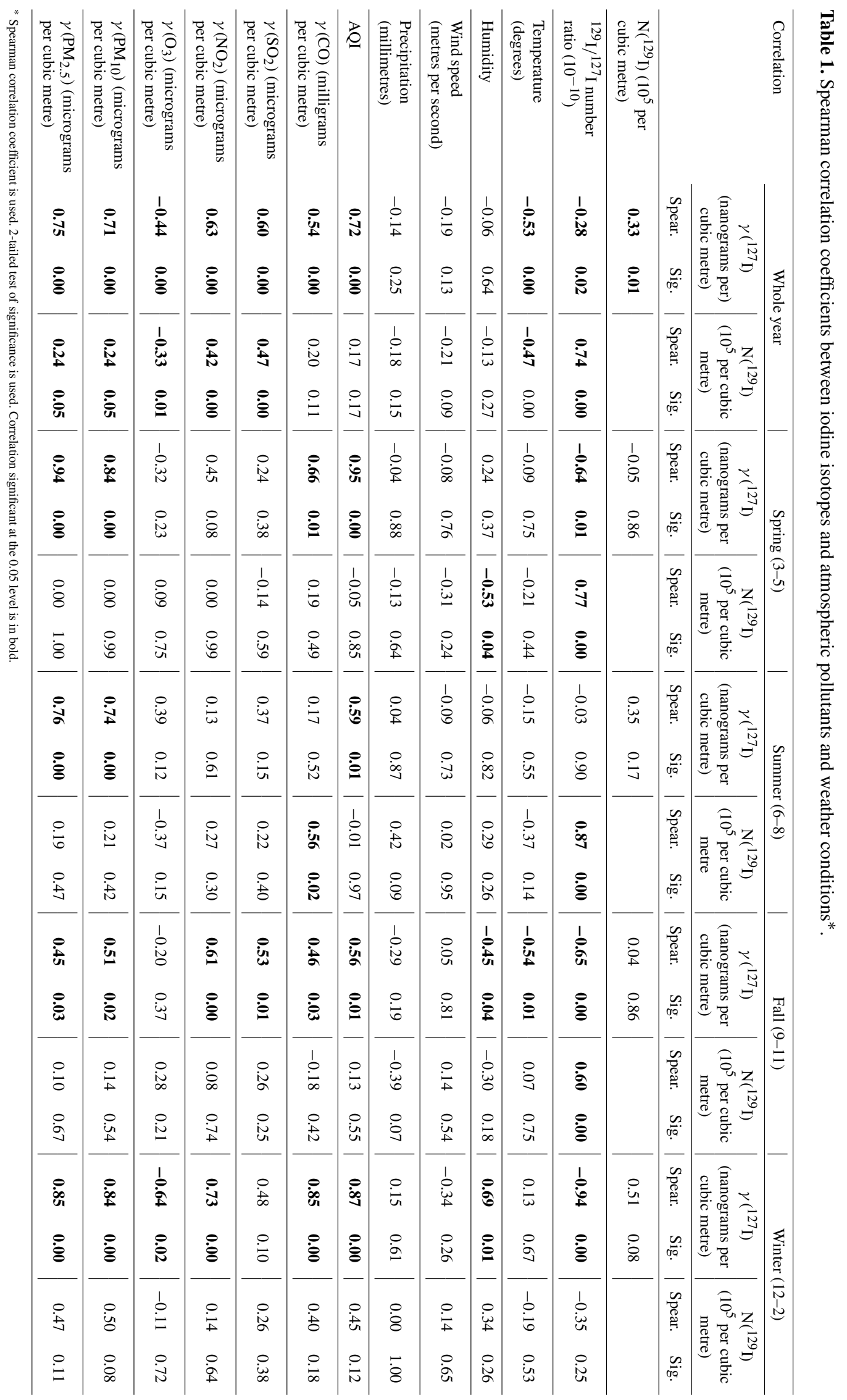




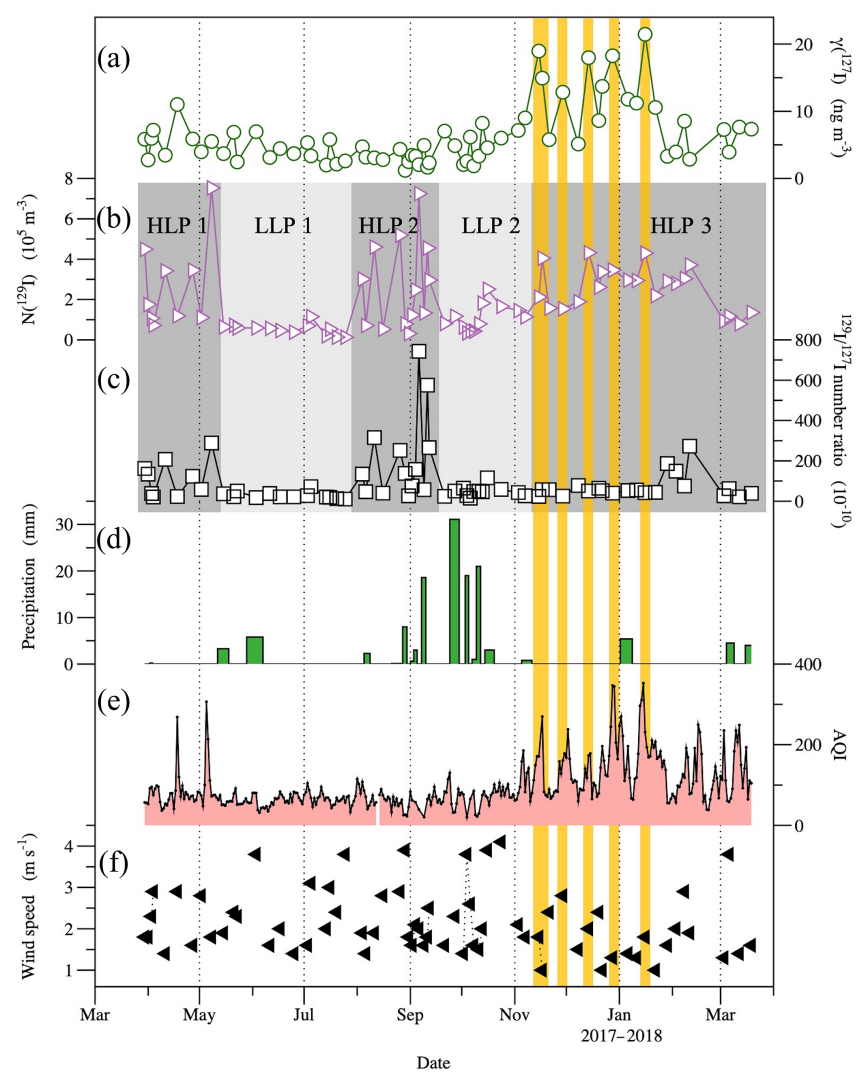

Figure 2. Temporal variation in (a) $\gamma\left({ }^{127} \mathrm{I}\right)$, (b) $\mathrm{N}\left({ }^{129} \mathrm{I}\right)$ and (c) ${ }^{129} \mathrm{I} /{ }^{127} \mathrm{I}$ number ratios in aerosol samples collected in Xi' an, China, from March 2017 to March 2018. The meteorological and air quality data includes (d) precipitation, (e) Air quality index (AQI,) and (f) wind speed. Orange bands indicate five heavy haze episodes corresponding with five ${ }^{127}$ I peaks. Three dark and two light grey shades in $(\mathbf{b}, \mathbf{c})$ demonstrate the high-level and low-level periods, HLP and LLP, respectively, for ${ }^{129} \mathrm{I}$ and the ${ }^{129} \mathrm{I} /{ }^{127} \mathrm{I}$ number ratio, alternatively dominated by the EAWM and EASM, respectively.

moisture from the Pacific Ocean and the Chinese seas might bring marine iodine. Whereas, the mean $\gamma\left({ }^{127} \mathrm{I}\right)$ in summer aerosol is $3.61 \pm 1.49 \mathrm{ng} \mathrm{m}^{-3}$, about 3 -fold lower than that in winter. The sampling location, Xi' an, is an inland city about $900 \mathrm{~km}$ away from the nearest coastline. The contribution of marine iodine to terrestrial surface system in winter is considered to be negligible when the site is over $400 \mathrm{~km}$ away from the ocean (Cohen, 1985). Taking sodium and calcium as reference elements for sea spray and direct volatilisation of iodine from the ocean and weathering of soil and rock, respectively, $\mathrm{He}(2012)$ has estimated that less than $0.04 \%$ and $5.2 \%$ of iodine was from direct marine contribution and weathering of soil and rock, respectively, in the precipitation in Zhouzhi County, Xi' an city. Despite being likely underestimated, marine iodine contribution in precipitation samples showed a declining trend with increasing distances of 20 to $1252 \mathrm{~km}$ from the sea. And no significant change in marine
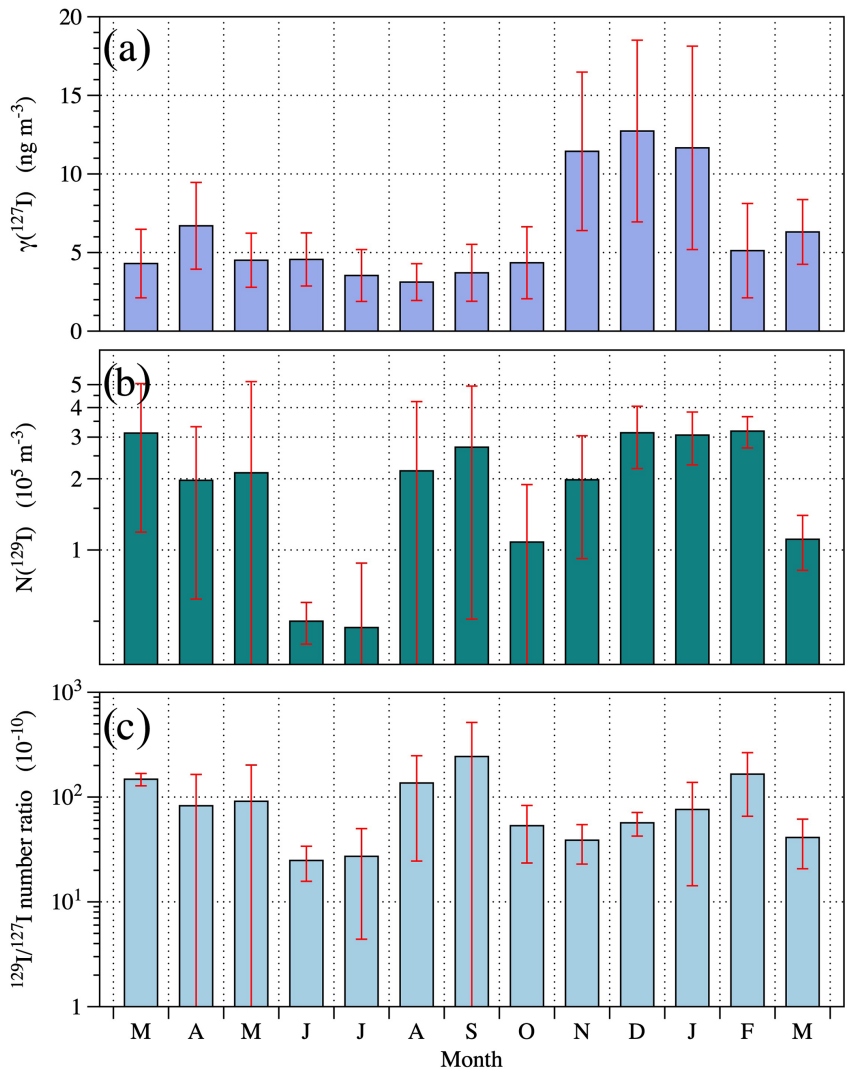

Figure 3. Monthly variation in (a) $\gamma\left({ }^{127} \mathrm{I}\right)$, (b) $\mathrm{N}\left({ }^{129} \mathrm{I}\right)$ and (c) ${ }^{129} \mathrm{I} /{ }^{127} \mathrm{I}$ number ratio in aerosols from March 2017 to March 2018.

contribution could be found over $100 \mathrm{~km}$ from the sea (He, 2012).

Iodine is also emitted from volatility of terrestrial soil and respiration of vegetation, which was estimated to be $2.27 \mu \mathrm{g} \mathrm{m}^{-2} \mathrm{~d}^{-1}$ in the form of $\mathrm{CH}_{3} \mathrm{I}$, on a global basis, over an active season of $240 \mathrm{~d}$, together with biome areas for temperate forest and wood lands $\left(28.5 \times 10^{12} \mathrm{~m}^{2}\right)$ and temperate grasslands $\left(31.9 \times 10^{12} \mathrm{~m}^{2}\right)$ (Sive et al., 2007). Dry deposition flux of iodine, however, can be calculated to be 5.83$40.7 \mu \mathrm{g} \mathrm{m}^{-2} \mathrm{~d}^{-1}$ based on aerosol ${ }^{127}$ I mass concentrations in

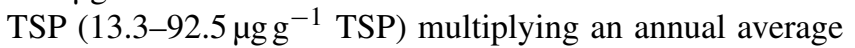
dustfall flux of $13.2 \mathrm{t}\left(\mathrm{km}^{-2} 30 \mathrm{~d}^{-1}\right)$ (Xi' an Bureau of Statistics, 2018). The uncertainty for the calculation is about $32 \%$ mainly due the large uncertainty in dustfall flux of about $31 \%$. Because of different land coverage between urban and forest-grassland in reference of Sive et al. (2007), terrestrial emission of iodine in the sampling site should be even lower than $2.27 \mu \mathrm{g} \mathrm{m}^{-2} \mathrm{~d}^{-1}$. The dry deposition flux of iodine in $\mathrm{Xi}$ ' an was therefore far beyond terrestrial sources of soil and vegetation, indicating they might be important iodine sources in summer but not in winter.

The significant increase in ${ }^{127} \mathrm{I}$ from summer to winter suggests that anthropogenic discharge of iodine is the domi- 

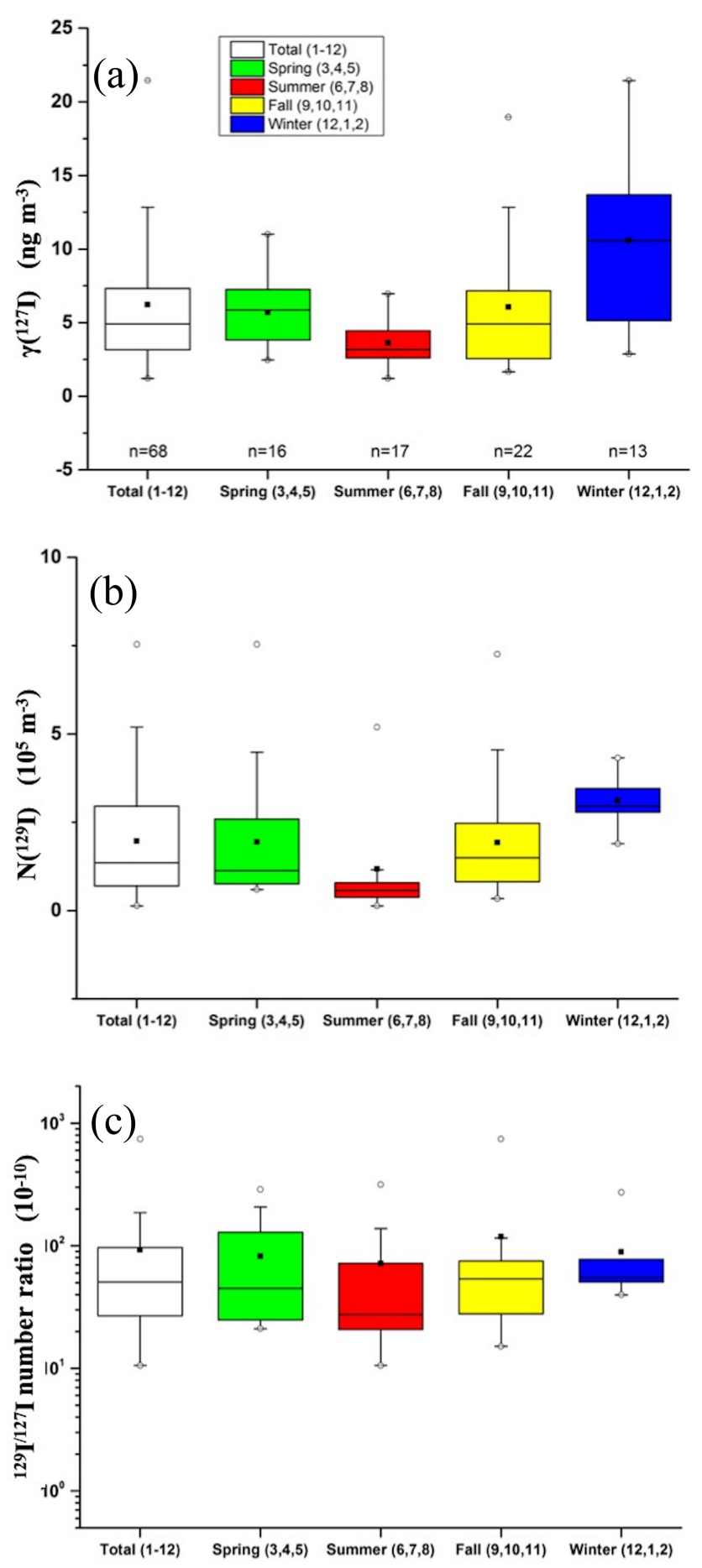

Figure 4. Seasonal variation in $\gamma\left({ }^{127} \mathrm{I}\right)$ (a), $\mathrm{N}\left({ }^{129} \mathrm{I}\right)$ (b) and ${ }^{129} \mathrm{I} /{ }^{127} \mathrm{I}$ number ratio (c) in aerosols collected in Xi' an, China, from March 2017 to March 2018. The boxes show the range from $25 \%$ to $75 \%$. Mean and median values are indicated with black solid squares and horizontal bars, respectively. The whisker indicates the upper and lower limits excluding outliers shown by dots. The outliers are defined as those 1.5 times greater than the interquartile range. nant source of ${ }^{127} \mathrm{I}$ in $\mathrm{Xi}$ ' an aerosol samples, mainly including combustion of biomass and fossil fuel (Wu et al., 2014). Biomass combustion generally occurs in summer harvest time, normally in later May and early June. In order to improve air quality, Xi' an government has banned biomass combustion since 2009. Additionally, no obvious change in ${ }^{127}$ I concentrations was found in May and June, indicating the biomass combustion is not the major source.

A recent study has confirmed that particulate iodine around two coal plants in Nanchang city, China, was greatly increased up to $36 \mathrm{ng} \mathrm{m}^{-3}$, and iodine concentrations within $9 \mathrm{~km}$ from the coal plants were much higher than that in non-coal sites (Duan, 2018). Coal is dominant in energy consumption structure. Coal consumption accounted for $72.7 \%$ of total energy consumption in Shaanxi Province in 2013. In 2017, the coal consumption in Guanzhong basin was 67.4 million t (Shaanxi Provincial Bureau of Statistics, 2018). The ${ }^{127}$ I concentration in coal produced in Shaanxi Province ranges from 0.39 to $6.53{\mu g^{-1}}^{-1}$ with a mean value of $1.47 \mathrm{\mu g} \mathrm{g}^{-1}$ (Wu et al., 2014). An atmospheric iodine emission factor that equals to the ratio of the iodine released into the atmospheric from the coal is from $78.8 \%$ to $99.4 \%$, depending on the coal combustion technology and emission control devices (Wu et al., 2014). If simply assuming anthropogenic iodine is solely from combustion of coal in the study area and the atmospheric iodine emission factor is $92 \%$, about $91 \mathrm{t}$ of ${ }^{127} \mathrm{I}$ could have been released into the atmosphere in the Guanzhong basin in 2017. Xi'an, a northern city in China, consumes more coal in the heating period from 15 November to $15 \mathrm{March}$, which aggravates iodine release from coal combustion. Thus, we suggest that coal combustion is the major source of ${ }^{127} \mathrm{I}$ in Xi' an urban aerosols in particular during the heating period of winter. This also suggests that ${ }^{127}$ I was regionally or locally input and can be treated as internal release.

\subsection{2 ${ }^{129}$ I}

The aerosol ${ }^{129} \mathrm{I}$ levels reported in the previous studies and this work can be categorised into three groups (Fig.5). (1) Compared to other investigating sites, aerosol $\mathrm{N}\left({ }^{129} \mathrm{I}\right)$ was less than $10^{6}$ atoms $\mathrm{m}^{-3}$ in Xi' an, north-west China. This low level is also found at those sites that are remote from the nuclear facilities in southern and central Europe, as well as Japan before the Fukushima accident (Hasegawa et al., 2017; Jabbar et al., 2013; Santos et al., 2005). The lowest $\mathrm{N}\left({ }^{129} \mathrm{I}\right)\left(<0.1 \times 10^{5}\right.$ atoms $\left.\mathrm{m}^{-3}\right)$ in aerosols have been found at two high-altitude sites of the Alps (about $3000 \mathrm{~m}$ above the sea level). (2) The high values beyond $10^{8}$ atoms $\mathrm{m}^{-3}$ have been reported at the sites directly contaminated either by nuclear reprocessing plants, such as Hanford, Sellafield and the reprocessing plant (WAK) at Karlsruhe, or by the Fukushima nuclear accident in 2011 (Brauer et al., 1973; Jackson et al., 2002; Wershofen and Aumann, 1989; Xu et al., 2015). (3) In between, aerosol $\mathrm{N}\left({ }^{129} \mathrm{I}\right)$ within the range from $10^{6}$ to 
$10^{8}$ atoms $\mathrm{m}^{-3}$ is mainly found in the sites and periods with global fallout from atmospheric nuclear weapon testing and from indirect contamination from nuclear fuel reprocessing plants (Brauer et al., 1973; Englund et al., 2010; Kadowaki et al., 2018; Tsukada et al., 1991; Zhang et al., 2016).

The source of ${ }^{129} \mathrm{I}$ is crucial for spatial and temporal distributions of ${ }^{129} \mathrm{I}$ in global scale. ${ }^{129} \mathrm{I} /{ }^{127} \mathrm{I}$ number ratios in the Xi' an aerosols range from $10.6 \times 10^{-10}$ to $743 \times 10^{-10}$, at least 3 orders of magnitude higher than the naturally produced ${ }^{129}$ I level $\left(1.5 \times 10^{-12}\right)$ (Fehn et al., 2005). This clearly indicates human nuclear activities are a dominant contributor to the increase in ${ }^{129} \mathrm{I}$ level in the environment. The level and source of ${ }^{129} \mathrm{I}$ in soil, vegetation, rain and river water samples have been previously investigated in the Xi' an region, where ${ }^{129} \mathrm{I} /{ }^{127} \mathrm{I}$ varied from $1.1 \times 10^{-10}$ to $43.5 \times 10^{-10}$ with a mean value of $20.6 \times 10^{-10}$ (Zhang et al., 2011). Aerosol ${ }^{129} \mathrm{I} /{ }^{127} \mathrm{I}$ number ratios were about 1 order of magnitude higher than those in other environmental media, indicating ${ }^{129} \mathrm{I}$ in Xi' an aerosols was not released by local soil suspension and vegetation release. Weathering of bedrock is not a major source of airborne ${ }^{129} \mathrm{I}$, since weathering just contributes $5 \%$ of stable iodine, and ${ }^{129} \mathrm{I}$ in bedrock can be considered even lower than the nature-produced ${ }^{129} \mathrm{I}$ level because of the continuous decay. Coal combustion contributes a large proportion of stable ${ }^{127} \mathrm{I}$ in winter, while the amount of ${ }^{129} \mathrm{I}$ in coal is almost negligible, because coal was formed in the Tertiary (2.58-66 million years) at the latest so that ${ }^{129} \mathrm{I}$ has been decayed out or in an extremely low value of $10^{-13}-10^{-10}$ for ${ }^{129} \mathrm{I} /{ }^{127} \mathrm{I}$. Thus, coal combustion is not a major source of atmospheric ${ }^{129} \mathrm{I}$.

Nuclear activities including the historic nuclear weapon testing sites, nuclear reactors, NFRPs in China and Europe, and underground nuclear weapon testing are considered. Two nuclear weapon testing sites, Semipalatinsk and Lop Nor, located upwind, may input ${ }^{129} \mathrm{I}$ into Xi' an region through soil resuspension and gaseous re-emission. However, evidence from the ${ }^{129} \mathrm{I}$ distribution in surface soils from upwind regions reveals that the two nuclear weapon testing sites have a limit impact on the atmospheric ${ }^{129} \mathrm{I}$ level in the remote regions farther than $1000 \mathrm{~km}$ from these test sites (Fan, 2013). This is also supported by the back-trajectory analysis that ${ }^{129}$ I concentration did not significantly rise when abundant air masses from Xinjiang passed through the Lop Nor test site on 28 December 2017 (Fig. S3g). Five nuclear power plants are in operation along the south-east coastal areas in China. ${ }^{129} \mathrm{I}$ data from seawater collected within $10 \mathrm{~km}$ from a Chinese nuclear power plant suggest that normal operation of reactors does not cause a significant increase in ${ }^{129} \mathrm{I}$ concentrations (He et al., 2011). Although information on the gaseous release of ${ }^{129} \mathrm{I}$ from these reactors is unknown, the low ${ }^{129} \mathrm{I} /{ }^{127} \mathrm{I}$ (about $7 \times 10^{-10}$ ) in the surface soil of southern China (Guangxi, Jiangxi and Fujian provinces) close to the reactors can confirm that there is no marked deposition from the gaseous release (Fan, 2013). Toyama et al. (2013) have shown a direct nearby influence of a pilot plant in
Tokaimura (Ibaraki Prefecture), Japan on the ${ }^{129}$ I deposition in Tokyo. Similarly, a pilot nuclear spent fuel reprocessing plant (NFRP) has been established and operated in Gansu Province, China, since 2010. This NFRP is located in an upwind area and about $1200 \mathrm{~km}$ north-east of Xi'an. During the sampling period in $2017 / 18$, no abnormally high ${ }^{129}$ I was observed; however this contribution cannot be neglected in the future operation and should be continuously monitored. In addition, the possible influence of the sixth underground nuclear weapon test conducted by North Korea on 3 September 2017 has been excluded based on the back and forward trajectories and the nuclear environmental monitoring around the Chinese north-east border by the government (Ministry of Environmental Protection of the People's Republic of China, 2017).

It is well documented that gaseous and liquid discharges from the NFRPs in Sellafield, United Kingdom, and La Hague, France, as well as the secondary emission from the contaminated seas and land, are the predominant source of ${ }^{129} \mathrm{I}$ in the modern atmosphere, particularly in the European environment (Jabbar et al., 2013). The two NFRPs are located from 50 to $55^{\circ} \mathrm{N}$, the westerly belt. The prevailing westerly winds throughout the year in the midlatitude act as a crucial pathway of ${ }^{129}$ I transport from its source to the whole midlatitude regions of the Northern Hemisphere, as observed in the sediment core from Jiaozhou Bay on the east coast of China (Fan et al., 2016). The 60 -year record of ${ }^{129} \mathrm{I}$ in a lacustrine sediment from the Philippines further shows that the EAWM plays an important role in transporting the midlatitude ${ }^{129} \mathrm{I}$ to the low-latitude regions (Zhang et al., 2018a). The feature of ${ }^{129} \mathrm{I}$ variation also shows that ${ }^{129} \mathrm{I}$ was at a high level in spring and winter when the EAWM is prevailing and at a low level in summer when the EASM is prevailing, supporting that ${ }^{129} \mathrm{I}$ is dominantly sourced from the long-range transport of European NFRPs discharges. In this case, ${ }^{129} \mathrm{I}$ is externally input, in contrast to the locally released stable ${ }^{127} \mathrm{I}$.

\subsection{Factors influencing temporal variation in iodine isotopes}

As discussed above, even though variation patterns of ${ }^{127} \mathrm{I}$ and ${ }^{129}$ I were similar, they were considerately influenced by many factors owing to their different sources. In this work, meteorological factors including precipitation, wind speed, temperature and dust storm events including, atmospheric circulation (in particular the EAM) and heavy air pollution periods are discussed.

\subsubsection{Meteorological factors}

Precipitation and wind speed. As discussed in Sect. S2, the influences of precipitation and wind speed on temporal changes in iodine isotopes are not significant (Fig. 2e and f). However, the winter days with an absence of wet precipita- 


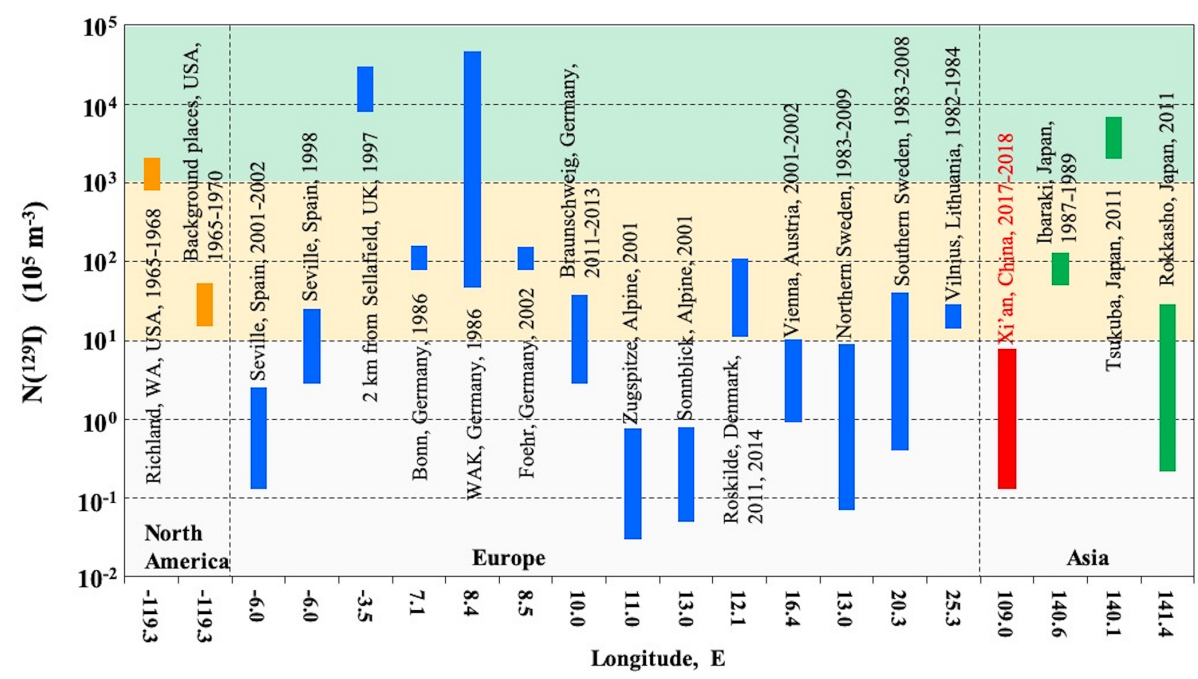

Figure 5. Comparison of aerosol ${ }^{129}$ I levels in Xi' an, China (red bars), with other investigations in North America (orange), Europe (blue) and East Asia (Green) distributed by longitude. The green, yellow and white bands are high $\left(>10^{8}\right.$ atoms $\left.\mathrm{m}^{-3}\right), \mathrm{middle}\left(10^{6}\right.$ to $10^{8}$ atoms $\left.\mathrm{m}^{-3}\right)$ and low $\left(<10^{6}\right.$ atoms $\left.\mathrm{m}^{-3}\right){ }^{129}$ I concentrations in aerosols.

tion and lower wind speed corresponded well to the heavy haze episodes when iodine concentrations, in particular stable ${ }^{127} \mathrm{I}$, were greatly increased, indicative of less dispersion. The details about haze influence on iodine will also be discussed in the following section.

Temperature. Temperature and its associated physiochemical processes and biological release of iodine from source regions might be reasons for the variation patterns. In summer, the temperature is about $20-40^{\circ} \mathrm{C}$ in the North Hemisphere, which is favourable for direct volatilisation of iodine from the surfaces of land and seas. Ozone in the air-sea boundary layer is suggested to act as an oxidant to transform iodide in seawater into volatile molecular iodine that enters into the air, which is believed more significant than the biological process (Carpenter et al., 2013). Ozone concentrations in summer are around $30 \mathrm{nmol} \mathrm{mol}^{-1}$, roughly 2 times higher than winter (Ayers et al., 1996), which may increase the re-emission rate of iodine from the ocean and ${ }^{129} \mathrm{I}$-contaminated sea surface into the air. Additionally, the bloom of phytoplankton and algae in summer, can release biogenic organic iodine into the air through a mechanism of anti-oxidation (Küpper et al., 2008). The temperature, ozone concentration and marine biomass greatly reduces in winter, which results in less iodine released from the source regions and this can be used to explain the relatively weak peaks in winter than in summer. As discussed above, ${ }^{127} \mathrm{I}$ and ${ }^{129} \mathrm{I}$ in Xi' an aerosols were mainly derived from coal combustion and long-range transport from Europe, respectively. The change in the release amount of ${ }^{127} \mathrm{I}$ and ${ }^{129} \mathrm{I}$ at the source regions is obviously not the determining factor for the changes in iodine isotopes since Xi' an is far from the oceans and the ${ }^{129} \mathrm{I}$ source regions. Furthermore, the seasonal variation in ${ }^{127} \mathrm{I}$ and ${ }^{129} \mathrm{I}$ with low levels in summer can also easily exclude the possibility of temperature influence.

In addition to atmospheric stability reflected by precipitation, wind and temperature, atmospheric boundary layer height determines the vertical dispersion scale of air pollution by thermal turbulent mixing, which might be a factor for variation in iodine isotopes. Since ${ }^{127} \mathrm{I}$ is locally input and ${ }^{129} \mathrm{I}$ is remotely transported from Europe, the influence of boundary layer height might be different for the two iodine isotopes. It will be further explored with longer temporal variation in iodine isotopes in the future.

Dust storms. Two severe dust storm events occurred in Xi' an in 17-18 April and 4-6 May 2017, as indicated by the peaks of air quality index (AQI) of 268 and 306, respectively. A ${ }^{127}$ I peak, $11.0 \mathrm{ng} \mathrm{m}^{-3}$, was observed on 18 April 2017, while ${ }^{127}$ I levels in other samples were almost below $6 \mathrm{ng} \mathrm{m}^{-3}$ in spring and summertime. Dust storms frequently occur in winter and spring in northern China and normally originate from the arid and semi-arid desert regions mainly located in Mongolia and north-west China. The first dust storm arrived the Guanzhong basin on 17 April 2017 and lasted until 19 April (China Meteorological Administration, 2018). The small peak of ${ }^{127} \mathrm{I}$ is likely attributed to the suspended particulate matter from the soil surface in the dust storm source. In contrast, variation in the ${ }^{129} \mathrm{I}$ level did not reflect the dust storm influence. The fact that ${ }^{129} \mathrm{I}$ was not correlated with particulate concentrations (Fig. S4), indicates that the extrinsic ${ }^{129}$ I is not related to the heavy particulate events, since the major dust source areas include Taklimakan desert, the Gobi Desert in Inner Mongolia and the Loess Plateau, where the ${ }^{129} \mathrm{I} /{ }^{127} \mathrm{I}$ number ratios in surface soil fell below $60 \times 10^{-10}$, apparently much lower than those in aerosols (Zhang et al., 2011). Furthermore, the back-trajectory anal- 
ysis also showed that the low ${ }^{129}$ I level on 18 April can be partially attributed to an ${ }^{129} \mathrm{I}$-poor low-altitude air mass $(<$ $900 \mathrm{~m}$ ) (Fig. S3a). This is because either the low-altitude air mass might be formed in ${ }^{129} \mathrm{I}$-poor inland areas, not from the ${ }^{129}$ I-rich European area, or else the long-range-transported ${ }^{129}$ I in low-altitude air mass could be easily lost by the topographic countercheck (Dong et al., 2018).

The second dust storm started from the south central Mongolia and west-central Inner Mongolia autonomous regions on 3 May, arrived at Xi' an on 5 May and retreated on 6 May. It is a pity that no sample was analysed in this event, but a significant ${ }^{129}$ I peak with value of $7.53 \times 10^{5}$ atoms $\mathrm{m}^{-3}$ was found after $3 \mathrm{~d}$ of this event (Fig. 2b). The back-trajectory analysis suggests the ${ }^{129}$ I peak on 8 May 2017 is found to relate to the downdraft originating from high altitude (2000$6000 \mathrm{~m})$ to low altitude $(500 \mathrm{~m})$ (Fig. S3b). This elevation of ${ }^{129}$ I after the dust storm events is likely attributed to the intensified winter monsoon and strong cold high pressure transporting greater ${ }^{129}$ I from Europe to China.

\subsubsection{Heavy haze episodes during 2017/18 winter}

A significantly positive correlation between ${ }^{127} \mathrm{I}$ and air quality index (AQI) was found with a high Spearman correlation coefficient of $0.72(p \ll 0.05)$ for the whole-year sampling period and an increased coefficient of 0.87 in winter (Table 1). The ${ }^{127}$ I concentration in winter can reach up to 10 times as much as in summer (Fig. 2a). Furthermore, five ${ }^{127}$ I peaks from 12.8 to $21.4 \mathrm{ng} \mathrm{m}^{-3}$ were clearly identified on 15 and 29 November, 14 and 28 December, and 16 January, respectively, which coincided well with the heavy haze episodes, with AQI mostly over 200, namely heavily polluted air (Fig. 2e). As discussed in Sect. 4.1, the irrelevance between ${ }^{127} \mathrm{I}$ and ${ }^{129} \mathrm{I}$ in aerosols for each season attributed to their different sources, also demonstrates that locally discharged iodine and externally input iodine are not contemporaneously subjected to formation of iodine-containing particles.

Further analysis showed close relationship between ${ }^{127} \mathrm{I}$ and six air pollutants, including $\mathrm{PM}_{10}, \mathrm{PM}_{2.5}, \mathrm{CO}, \mathrm{SO}_{2}, \mathrm{NO}_{2}$ and $\mathrm{O}_{3}$ (Table 1 and Fig. S4). In spring and summer, the high correlation between ${ }^{127}$ I and AQI can be attributed to the high correlation of ${ }^{127} \mathrm{I}$ with $\mathrm{PM}_{10}$ and $\mathrm{PM}_{2.5}$. In fall and winter, ${ }^{127} \mathrm{I}$, is significantly positively correlated with $\mathrm{PM}_{10}$, $\mathrm{PM}_{2.5}, \mathrm{CO}, \mathrm{SO}_{2}$ and $\mathrm{NO}_{2}$ and negatively correlated with $\mathrm{O}_{3}$. In contrast, there is no such good agreement between ${ }^{129} \mathrm{I}$ and these gaseous pollutants. Despite that, three ${ }^{129}$ I peaks were found on 15 November 2017, 14 December 2017 and 16 January 2018 , which corresponded well with high ${ }^{127}$ I concentrations (Fig. 2a and b) during the haze episodes. This reflects that the formation mechanism of iodine-containing aerosols might be seasonally different. However, the three peaks of ${ }^{129} \mathrm{I}$ in aerosols during the heavy haze episodes suggest that local and external iodine are likely subjected to subsequent growth of particles and capture by particles due to a longer residence time in stagnant weather conditions.

\subsubsection{Impact of the EAM for long-range transport of ${ }^{129} \mathrm{I}$}

Increasing evidence has suggested that the prevailing westerly and the EAM system act as crucial driving forces and pathways for transport of the ${ }^{129} \mathrm{I}$ derived from European NFRPs from Europe to East Asia and even low-latitude south-east Asia (Fan et al., 2016; Zhang et al., 2018a). Monthly variations in atmospheric ${ }^{129} \mathrm{I}$ in Japan also showed a clear pattern of low ${ }^{129} \mathrm{I}$ deposition in summer and high ${ }^{129} \mathrm{I}$ deposition in winter, which is also attributed to the impact of the EAM (Hasegawa et al., 2017; Kadowaki et al., 2018; Toyama et al., 2013). In this work, seasonal variation in ${ }^{129}$ I was identical to the observation in the previous studies (Toyama et al., 2013). However, the day-resolution variation patterns of ${ }^{129} \mathrm{I}$ and ${ }^{129} \mathrm{I} /{ }^{127} \mathrm{I}$ in Xi' an, distinct from monthly variation in Japan, showed three periods with high levels and two periods with low levels, indicating a more complex influence of the EAM in the typically continental monsoon climate city, Xi' an.

The whole-year time series can be divided into five periods with three high-level periods (HLP) from (a) late March to early May (HLP 1), (b) middle August to early September (HLP 2) and (c) middle November 2017 to late February 2018 (HLP 3), as well as two low-level periods (LLP) from (d) early May to middle August (LLP 1) and (e) middle September to early November 2017 (LLP 2) (Fig. 2b and c). ${ }^{129}$ I levels in the three HLPs fell within the range of (1.98$2.41) \times 10^{5}$ atoms $\mathrm{m}^{-3}$, which is $3-5$ times higher than those during the two LLPs with $(0.49-0.66) \times 10^{5}$ atoms $\mathrm{m}^{-3}$ (Table S1). The relative standard deviation shows much higher variability during HLP 1 and 2 from $91 \%$ to $109 \%$ in contrast to the variability in other clusters of less than $60 \%$.

The significant difference between the HLPs and LLPs suggests the transportation process of ${ }^{129} \mathrm{I}$ is obviously distinct. The westerly is a crucial driving force of ${ }^{129} \mathrm{I}$ from the NFRP point sources and their contaminated seas, which are labelled as having a high ${ }^{129} \mathrm{I}$ level, up to $10^{-6}$ for the ${ }^{129} \mathrm{I} /{ }^{127} \mathrm{I}$ number ratio (Michel et al., 2012; Zhang et al., 2016) (Fig. 1a). Due to interplay between the westerly and EAWM (An et al., 2012), EAWM inherits the high ${ }^{129} \mathrm{I}$ feature of $10^{-7}-10^{-9}$ for a ${ }^{129} \mathrm{I} /{ }^{127} \mathrm{I}$ number ratio in the long-distance transport process. Therefore, the HLP 1 and 3 were strongly affected by the EAWM prevailing from early September to early May in 2017. Compared to the violent fluctuation of ${ }^{129}$ I in spring (HLP 1), the weak fluctuations of HLP 3 in winter might be attributed to a relatively stable interaction process between the strengthened westerly and the EAWM. In addition, the ${ }^{129} \mathrm{I}$ level in March 2018 was much less than that in March 2017, seeming to be a consequence of a weaker EAWM strength in March 2018 compared to in March 2017. This is in good agreement with the EAWM in- 
dices of 2.04 in 2017 and -1.86 in the 2018 MODES forecast monitor (National Climate Center of China Meteorological Administration, 2019). HLP 2 was a different case from HLPs 1 and 3, since the period should be under control of the EASM.

The EASM originates from the Pacific and Indian tropical regions under the role of subtropical highs and transports moisture from the ocean to East Asia starting in early summer. ${ }^{129} \mathrm{I} /{ }^{127} \mathrm{I}$ number ratios in the Pacific Ocean, the East China Sea and the Indian Ocean are as low as $10^{-10}$ (Liu et al., 2016; Povinec et al., 2011). Even after the Fukushima accident, ${ }^{129} \mathrm{I} /{ }^{127} \mathrm{I}$ number ratios are still less than $40 \times 10^{-10}$ in the western Pacific Ocean (Guilderson et al., 2014). Thus, the EASM is poor in ${ }^{129} \mathrm{I}$ in comparison to the winter monsoon. This is in good agreement with the low ${ }^{129}$ I level during the two LLPs (Fig. 2b). The $850 \mathrm{hPa}$ water vapour transmission flow field showed the south-east wind moisture moving northward to the north of $35^{\circ} \mathrm{N}$ on 2 May, followed by another two outbreaks on 21 May and 3 June (Fig. S5), indicative of a EAWM retreat and a EASM advance. During this period, ${ }^{129} \mathrm{I}$ dropped abruptly from $3.45 \times 10^{5}$ atoms $\mathrm{m}^{-3}$ on 27 April to $1.10 \times 10^{5}$ atoms $\mathrm{m}^{-3}$ on 2 May, followed by a maximum on 8 May; then there was a sudden decline to $0.64 \times 10^{5}$ atoms $\mathrm{m}^{-3}$ on 15 May. The violet fluctuation of ${ }^{129}$ I is likely caused by the onset of the EASM, which is quite violent with stepwise northward jumps. This conclusion is fully supported by previous metrological observations (Ding and Chan, 2005). As the EASM moved into the active stage in mid-May, the ${ }^{129} \mathrm{I}$ level was low and in a relatively stable state, as shown in LLP 1.

After the active stage of the EASM, however, it is unexpected that increased and variable ${ }^{129}$ I levels were observed from middle August to early September (HLP 2). The ${ }^{129}$ I peak on 6 September 2017 was the highest throughout the sampling year. The back-trajectory model shows that five low-altitude air masses $(<1000 \mathrm{~m}$ above ground level) from the Baltic Sea moved fast eastward and arrived at the Guanzhong basin within $5 \mathrm{~d}$ (Fig. S3e). The Baltic Sea contains a high ${ }^{129}$ I concentration due to the water exchange with the North Sea that receives over $100 \mathrm{~kg} \mathrm{yr}^{-1}{ }^{129}$ I from La Hague and Sellafield NFRPs (Snyder et al., 2010). Therefore, ${ }^{129}$ I peak observed here indicates that there is interplay between the ${ }^{129}$ I-enriched westerly and the EASM, the latter of which was retreating to the south. It is reported that Xi'an enters into the EASM break stage during this time based on rainfall data (Ding and Chan, 2005). The intensive interaction between westerly winds and the EASM facilitates the formation of rainfall at their confluence area, resulting in the drastically fluctuating ${ }^{129} \mathrm{I}$ levels. Therefore, the elevated and variable ${ }^{129}$ I levels in HLP 2 can be attributed to the EASM break stage.

After the break stage with significant ${ }^{129}$ I fluctuation, the second LLP of ${ }^{129}$ I from 21 September to 11 October (LLP 2) occurred when the summer monsoon moved into the revival stage (Fig. 2b). Despite being lower than in the break period, the ${ }^{129} \mathrm{I}$ level in this period was slightly increased from $0.49 \times 10^{5}$ atoms $\mathrm{m}^{-3}$ in the active stage to $0.66 \times 10^{5}$ atoms $\mathrm{m}^{-3}$ in the revival stage. After the active-break-revival cycle of summer monsoon, reflected by a low-high-low ${ }^{129} \mathrm{I}$ level, the ${ }^{129}$ I level increased stepwise since mid-October, suggesting the EAWM had taken the place of the EASM in the Guanzhong basin and lasted until March next year.

To quantitatively characterise the influence of the EAM on the variation in ${ }^{129} \mathrm{I}, Z$-normalised ${ }^{129} \mathrm{I}$ concentrations and ${ }^{129} \mathrm{I} /{ }^{127} \mathrm{I}$ number ratios were used to build a quantitative model during the winter monsoon and different stages of the summer monsoon including onset, active, break, revival and retreat (Fig. 6). The value of $\mathrm{Z}\left({ }^{129} \mathrm{I}\right)$ varies from -1.11 to 3.38 with a median value of -0.29 and $\mathrm{Z}\left({ }^{129} \mathrm{I} /{ }^{127} \mathrm{I}\right.$ number ratio) from -0.66 to 5.26 with a median value of -0.34 . Based on the observation during 2017/18 in the Guanzhong basin, when $\mathrm{Z}\left({ }^{129} \mathrm{I}\right)$ is less than -0.5 and $\mathrm{Z}\left({ }^{129} \mathrm{I} /{ }^{127} \mathrm{I}\right.$ number ratio) is smaller than 0 , this period is in good agreement with the onset, active and revival stages of the EASM. During the stable active stage, $Z$ scores for ${ }^{129} \mathrm{I}$ and ${ }^{129} \mathrm{I} /{ }^{127} \mathrm{I}$ were minimal, which was followed by the second lowest value during the revival stage. The onset and break stage showed a much larger fluctuation with $Z$ scores changing from -0.8 to -0.3 . The break stage of the East Asian summer monsoon is an exception, which exists with alternative influences from both factors in our studied region. The $\mathrm{Z}\left({ }^{129} \mathrm{I}\right)$ values from 1.57 to 1.96 for the break stages were much higher than the period controlled by the East Asian winter monsoon with Z $\left({ }^{129} \mathrm{I}\right)$ from -0.5 to 1.53 . This result clearly confirms that the EAM plays a decisive role on the temporal variation and long-range transport of not only ${ }^{129} \mathrm{I}$ but also other air pollutants (i.e. persisting organic pollutants or inorganic air pollutants) in Chinese monsoon-affected regions.

\subsection{Atmospheric background level of ${ }^{129} \mathrm{I} /{ }^{127}$ I number ratio}

For the purpose of nuclear environment safety monitoring, the average ${ }^{129} \mathrm{I} /{ }^{127} \mathrm{I}$ number ratio of $(92.7 \pm 124) \times 10^{-10}$ can be simply regarded as the atmospheric background level of ${ }^{129} \mathrm{I}$ in north-west China. The previous studies on ${ }^{129} \mathrm{I}$ environmental baseline have never carefully investigated the influence of weather on time variation in ${ }^{129}$ I. Here our dayresolution ${ }^{129} \mathrm{I}$ dataset in this monsoon climate city showed that time variation in the atmospheric baseline level related to metrological conditions, heavy haze events and atmospheric circulation, has to be carefully considered and used for better evaluation of the impact of possible nuclear incidents in a practical way. Particularly, a pilot nuclear reprocessing plant located upwind to Xi' an, might be extended and will be a source of radionuclides in the future. The baseline established in this work is, therefore, of significance to monitor nuclear environmental safety for the long-term and to sensitively assess the impact of nuclear incidents and apply on environmental process tracing. 


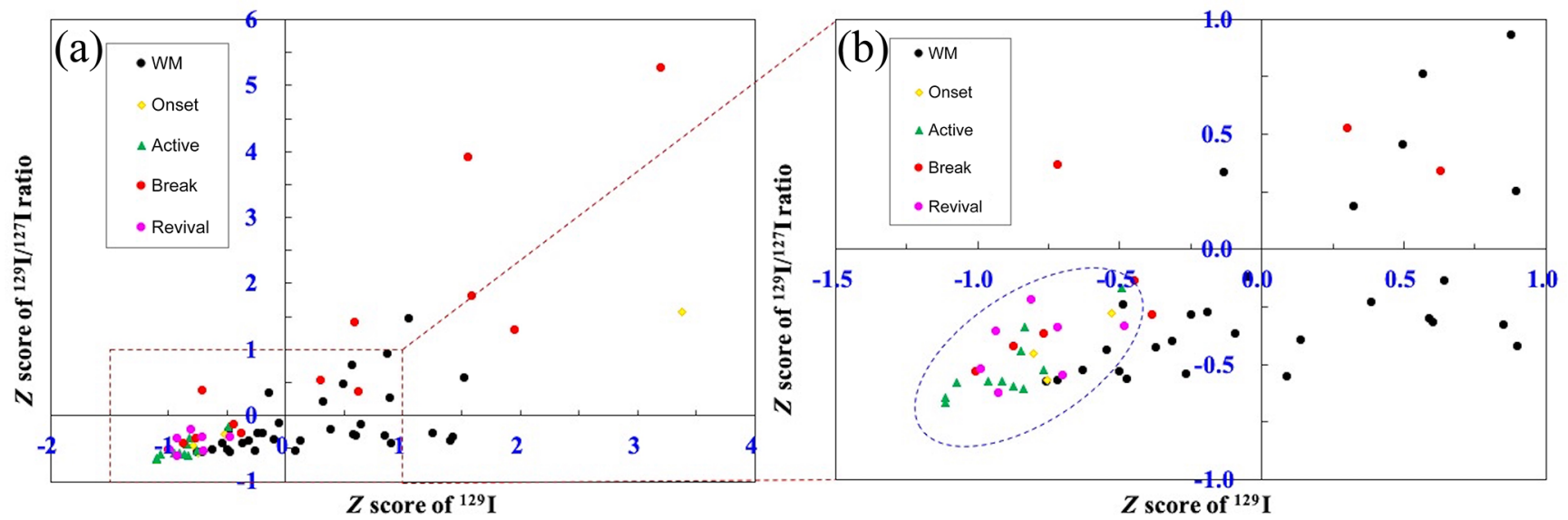

Figure 6. Two-dimensional graph of $Z$-score-normalised ${ }^{129} \mathrm{I}$ concentrations and ${ }^{129} \mathrm{I} /{ }^{127} \mathrm{I}$ number ratios, suggesting the refined features of the East Asian summer (onset, active, break and revival in yellow diamond, green triangle, red circle and pink circle, respectively) and winter monsoons (WM; black dot) (a). The coloured symbols clearly demonstrate a detailed onset-active-break-revival cycle for the summer monsoon with $Z_{129} \mathrm{I} \leq-0.5$ and $Z_{\text {Ratio }} \leq 0$, as illustrated in the blue oval area (b).

\section{Conclusions}

The study firstly presents a high-resolution temporal variation in atmospheric ${ }^{127} \mathrm{I}$ and ${ }^{129} \mathrm{I}$ in north-west China, showing the vivid seasonal characteristics of iodine isotopes and an ${ }^{129} \mathrm{I} /{ }^{127} \mathrm{I}$ baseline ratio of $(92.7 \pm 124) \times 10^{-10}$. Variation in ${ }^{127}$ I strongly linked with atmospheric pollution and heavy haze episodes, particularly in winter, indicates that ${ }^{127} \mathrm{I}$ in $\mathrm{Xi}$ 'an aerosols is mainly derived from combustion of fossil fuel. Aerosol ${ }^{129}$ I mainly originates from European nuclear reprocessing plants through long-range transport, and its temporal variation is strongly dominated by the interplay of the East Asian winter and summer monsoon. Previous studies on temporal changes in atmospheric ${ }^{129} \mathrm{I}$ in other monsoonal regions showed a simple pattern with the lowest level in summer and the highest in winter, while our dayresolution dataset showed that high ${ }^{129}$ I levels could be found in summertime due to the break of the East Asian summer monsoon. The locally input ${ }^{127} \mathrm{I}$ and exogenous ${ }^{129} \mathrm{I}$ were greatly increased during haze events, reflecting the possible role of iodine in the formation of urban fine particles, therefore, further investigations are expected to focus on the speciation of iodine isotopes for mechanism study of iodine's impact on air pollution.

Data availability. All the data generated during the study appear in the article.

Supplement. The supplement related to this article is available online at: https://doi.org/10.5194/acp-20-2623-2020-supplement.
Author contributions. LZ, XH and SX designed and optimised the experiment. LZ and NC performed the experiment, with the help of PC and YF. TF collected the air pollutant data. LZ, TF, PC and YF created the figures. The data analysis and interpretation were carried out by LZ, XH, SX, TF and NC. LZ prepared the paper, with contributions from all coauthors.

Competing interests. The authors declare that they have no conflict of interest.

Acknowledgements. Luyuan Zhang gratefully acknowledges Qi Liu, Miao Fang, Yanyun Wang, Lin Wang and Jie Zhou at IEECAS for their kind help on AMS measurement, sample collection and figure drawing. We acknowledge the two anonymous referees and editor for their constructive comments.

Financial support. This work was supported by the National Natural Science Foundation of China (grant nos. 11605207, 41603125 and 41991252), the Youth Innovation Promotion Association of CAS (grant no. 2019401), the Ministry of Science and Technology basic project (grant no. 2015FY110800), the Bureau of International Co-operation, CAS (grant no. 132B61KYSB20180003), and the National Research Program for Key Issues in Air Pollution Control (grant no. DQGG0105).

Review statement. This paper was edited by Jan Kaiser and reviewed by two anonymous referees. 


\section{References}

An, Z., Colman, S. M., Zhou, W., Li, X., Brown, E. T., Jull, A. J. T., Cai, Y., Huang, Y., Lu, X., Chang, H., Song, Y., Sun, Y., Xu, H., Liu, W., Jin, Z., Liu, X., Cheng, P., Liu, Y., Ai, L., Li, X., Liu, X., Yan, L., Shi, Z., Wang, X., Wu, F., Qiang, X., Dong, J., Lu, F., and $\mathrm{Xu}, \mathrm{X}$.: Interplay between the Westerlies and Asian monsoon recorded in Lake Qinghai sediments since $32 \mathrm{ka}$, Scientific Reports, 2, 619, https://doi.org/10.1038/srep00619, 2012.

Ayers, G. P., Penkett, S. A., Gillett, R. W., Bandy, B., Galbally, I. E., Meyer, C. P., Elsworth, C. M., Bentley, S. T., and Forgan, B. W.: The annual cycle of peroxides and ozone in marine air at Cape Grim, Tasmania, J. Atmos. Chem., 23, 221-252, https://doi.org/10.1007/BF00055155, 1996.

Brauer, F. P., Rieck, H. G. J., and Hooper, R. L.: Particulate and gaseous atmospheric iodine concentrations, International Atomic Energy Agency (IAEA), Battelle Pacific Northwest Laboratories, Washington, USA, 1973.

Carpenter, L. J., MacDonald, S. M., Shaw, M. D., Kumar, R., Saunders, R. W., Parthipan, R., Wilson, J., and Plane, J. M. C.: Atmospheric iodine levels influenced by sea surface emissions of inorganic iodine, Nat. Geosci., 6, 108-111, https://doi.org/10.1038/ngeo1687, 2013.

Cheng, N., Duan, L., Xiu, G., Zhao, M., and Qian, G.: Comparison of atmospheric $\mathrm{PM}_{2.5}$-bounded mercury species and their correlation with bromine and iodine at coastal urban and island sites in the eastern China, Atmos. Res., 183, 17-25, https://doi.org/10.1016/j.atmosres.2016.08.009, 2017.

China Meteorological Administration: Sandstorm in northwest China and central and western Inner Mongolia, available at: http://www.cma.gov.cn/2011xwzx/2011xqxxw/2011xzytq/ 201704/t20170417_407699.html, last access: 10 October 2018.

Cohen, B. L.: The origin of I in soil and the ${ }^{129} \mathrm{I}$ problem, Health Phys., 49, 279-285, 1985.

Ding, Y. and Chan, J. C. L.: The East Asian summer monsoon: An overview, Meteorol. Atmos. Phys., 89, 117-142, https://doi.org/10.1007/s00703-005-0125-z, 2005.

Dong, Z., Shao, Y., Qin, D., Zhang, L., Hou, X., Wei, T., Kang, S., and Qin, X.: Insight Into Radio-Isotope ${ }^{129}$ I Deposition in Fresh Snow at a Remote Glacier Basin of Northeast Tibetan Plateau, China, Geophys. Res. Lett., 45, 6726-6733, https://doi.org/10.1029/2018GL078480, 2018.

Duan, D.: Concentration Characteristics of Atmospheric Particulate Matters and Iodine in Coal-fired Area, M.S. thesis, Nanchang University, China, 2018.

Englund, E., Aldahan, A., Hou, X., Possnert, G., and Soderstrom, C.: Iodine (I-129 and I-127) in aerosols from northern Europe, Nucl. Instrum. Meth. B, 268, 1139-1141, 2010.

Fan, Y.: Spatial distribution of ${ }^{129} \mathrm{I}$ in Chinese surface soil and preliminary study on the ${ }^{129} \mathrm{I}$ chronology, PhD thesis, Institute of Earth Environment, Chinese Academy of Sciences, China, 2013.

Fan, Y., Hou, X., Zhou, W., and Liu, G.: I record of nuclear activities in marine sediment core from Jiaozhou Bay in China, J. Environ. Radioactiv., 154, 15-24, https://doi.org/10.1016/j.jenvrad.2016.01.008, 2016.

Fehn, U., Moran, J. E., Snyder, G. T., and Muramatsu, Y.: The initial ${ }^{129} \mathrm{I} / \mathrm{I}$ ratio and the presence of "old" iodine in continental margins, Nucl. Instrum. Meth. B, 259, 496-502, 2005.
Fuge, R. and Johnson, C.: The geochemistry of iodine - a review, Environ. Geochem. Hlth., 8, 31-54, https://doi.org/10.1007/BF02311063, 1986.

Gao, Y., Sun, M., Wu, X., Liu, Y., Guo, Y., and Wu, J.: Concentration characteristics of bromine and iodine in aerosols in Shanghai, China, Atmos. Environ., 44, 4298-4302, https://doi.org/10.1016/j.atmosenv.2010.05.047, 2010.

Guilderson, T. P., Tumey, S. J., Brown, T. A., and Buesseler, K. O.: The 129-iodine content of subtropical Pacific waters: impact of Fukushima and other anthropogenic 129-iodine sources, Biogeosciences, 11, 4839-4852, https://doi.org/10.5194/bg-114839-2014, 2014.

Hasegawa, H., Kakiuchi, H., Akata, N., Ohtsuka, Y., and Hisamatsu, S.: Regional and global contributions of anthropogenic iodine129 in monthly deposition samples collected in North East Japan between 2006 and 2015, J. Environ. Radioactiv., 171, 65-73, https://doi.org/10.1016/J.JENVRAD.2017.01.027, 2017.

He, C., Hou, X., Zhao, Y., Wang, Z., Li, H., Chen, N., Liu, Q., Zhang, L., Luo, M., Liang, W., Fan, Y., and Zhao, X. L.: ${ }^{129} \mathrm{I}$ level in seawater near a nuclear power plant determined by accelerator mass spectrometer, Nucl. Instrum. Meth. A, 632, 152-156, https://doi.org/10.1016/j.nima.2010.12.182, 2011.

He, L.: Iodine concentration, chemical speciation and their distribution in atmospheric precipitation and soil, M.S. thesis, Nanchang University, China, 2012.

Hou, X., Aldahan, A., Nielsen, S. P., Possnert, G., Hou, X., Aldahan, A., Nielsen, S. P., and Possnert, G.: Time Series of I-129 and I-127 Speciation in Precipitation from Denmark, Environ. Sci. Technol., 43, 6522-6528, https://doi.org/10.1021/es9012678, 2009.

Jabbar, T., Wallner, G., and Steier, P.: A review on ${ }^{129} \mathrm{I}$ analysis in air, J. Environ. Radioactiv., 126, 45-54, 2013.

Jackson, D., Ibrahimi, F., Fulker, M. J., Parry, S. J., and Rackham, K.: The effect of chemical speciation on the impact of I discharges to atmosphere from BNFL Sellafield, Cumbria, Radioprotection, 37, 459-464, 2002.

Kadowaki, M., Katata, G., Terada, H., Suzuki, T., Hasegawa, H., Akata, N., and Kakiuchi, H.: Impacts of anthropogenic source from the nuclear fuel reprocessing plants on global atmospheric iodine-129 cycle: A model analysis, Atmos. Environ., 184, 278291, https://doi.org/10.1016/j.atmosenv.2018.04.044, 2018.

Küpper, F. C., Carpenter, L. J., McFiggans, G. B., Palmer, C. J., Waite, T. J., Boneberg, E.-M., Woitsch, S., Weiller, M., Abela, R., Grolimund, D., Potin, P., Butler, A., Luther, G. W. 3rd, Kroneck, P. M. H., Meyer-Klaucke, W., and Feiters, M. C.: Iodide accumulation provides kelp with an inorganic antioxidant impacting atmospheric chemistry, P. Natl. Acad. Sci. USA, 105, 6954-6958, 2008.

Liu, D., Hou, X., Du, J., Zhang, L., and Zhou, W.: ${ }^{129} \mathrm{I}$ and its species in the East China Sea: level, distribution, sources and tracing water masses exchange and movement, Scientific Reports, 6, 36611, https://doi.org/10.1038/srep36611, 2016.

McFiggans, G., Plane, J. M. C., Allan, B. J., Carpenter, L. J., Coe, H., and O'Dowd, C.: A modeling study of iodine chemistry in the marine boundary layer, J. Geophys. Res., 105, 14371-14385, https://doi.org/10.1029/1999JD901187, 2000.

Michel, R., Daraoui, A., Gorny, M., Jakob, D., Sachse, R., Tosch, L., Nies, H., Goroncy, I., Herrmann, J., Synal, H. A., Stocker, M., and Alfimov, V.: Iodine-129 and iodine-127 in European seawa- 
ters and in precipitation from Northern Germany, Sci. Total Environ., 419, 151-169, 2012.

Ministry of Environmental Protection of the People's Republic of China: Environmental radiation monitoring results of the sixth North Korean nuclear test in the northeast border and surrounding areas, available at: http://www.zhb.gov.cn/gkml/, last access: 3 November 2017.

Moran, J. E., Oktay, S. D., Santschi, P. H., and Schink, D. R.: Atmospheric dispersal of iodine-129 from nuclear fuel reprocessing facilities, Environ. Sci. Technol., 33, 2536-2542, 1999.

National Climate Center of China Meteorological Administration: MODES forecast monitor (NCEP I): East Asian Winter Monsoon Index, available at: https://cmdp.ncc-cma.net/pred/cn_peace.php?eYear=2017\& eMonth=5\&search=BE\&product=EAWM.MODES\#search, last access: 8 July 2019.

Povinec, P. P., Breier, R., Coppola, L., Groening, M., Jeandel, C., Jull, A. J. T., Kieser, W. E., Lee, S. H., Liong, W. K., Morgenstern, U., Park, Y. H., and Top, Z.: Tracing of water masses using a multi isotope approach in the southern Indian Ocean, Earth Planet. Sc. Lett., 302, 14-26, 2011.

Saiz-Lopez, A., Gómez Martín, J. C., Plane, J. M. C., Saunders, R. W., Baker, A. R., Von Glasow, R., Carpenter, L. J., and McFiggans, G.: Atmospheric chemistry of iodine, Chem. Rev., 112, 1773-1804, 2012.

Santos, F. J., López-Gutiérrez, J. M., García-León, M., Suter, M., and Synal, H. A.: Determination of ${ }^{129} \mathrm{I} /{ }^{127} \mathrm{I}$ in aerosol samples in Seville (Spain), J. Environ. Radioactiv., 84, 103-109, 2005.

Shaanxi Provincial Bureau of Statistics: Report of industrial coal reduction in Guanzhong Basin in 2017, Xi'an, China, available at: http://www.shaanxitj.gov.cn/site/1/html/126/131/138/17703. htm, last access: 10 October 2018.

Sive, B. C., Varner, R. K., Mao, H., Talbot, R., Blake, D. R., and Wingenter, O. W.: A large terrestrial source of methyl iodide, Geophys. Res. Lett., 34, L17808, https://doi.org/10.1029/2007GL030528, 2007.

Snyder, G., Aldahan, A., Aldahan, A., and Possnert, G.: Global distribution and long-term fate of anthropogenic ${ }^{129} \mathrm{I}$ in marine and surface water reservoirs, Geochem. Geophy. Geosy., 11, 1-19, 2010.

Toyama, C., Muramatsu, Y., Igarashi, Y., Aoyama, M., and Matsuzaki, H.: Atmospheric fallout of ${ }^{129} \mathrm{I}$ in Japan before the Fukushima accident: Regional and global contributions (1963-2005), Environ. Sci. Technol., 47, 8383-8390, https://doi.org/10.1021/es401596z, 2013.

Tsukada, H., Ishida, J. and Narita, O.: Particle-size distributions of atmospheric ${ }^{129} \mathrm{I}$ and ${ }^{127} \mathrm{I}$ aerosols, Atmos. Environ. A-Gen., 25, 905-908, https://doi.org/10.1016/0960-1686(91)90132-Q, 1991.
Wershofen, H. and Aumann, D. C.: Iodine-129 in the environment of a nuclear fuel reprocessing plant: VII. Concentrations and chemical forms of ${ }^{129} \mathrm{I}$ and ${ }^{127} \mathrm{I}$ in the atmosphere, J. Environ. Radioactiv., 10, 141-156, 1989.

Whitehead, D. C.: The distribution and transformations of iodine in the environment, Environ. Int., 10, 321-339, https://doi.org/10.1016/0160-4120(84)90139-9, 1984.

World Nuclear Association: http://www.world-nuclear.org/, last access: 9 January 2017.

Wu, D., Du, J., Deng, H., Wang, W., Xiao, H., and Li, P.: Estimation of atmospheric iodine emission from coal combustion, Int. J. Environ. Sci. Te., 11, 357-366, https://doi.org/10.1007/s13762013-0193-4, 2014.

Xi'an Bureau of Statistics: Xi'an Statistics Yearbook, available at: http://tjj.xa.gov.cn/ptl/def/def/2017/zk/indexch.htm, last access: 19 December 2018

Xu, S., Xie, Z., Li, B., Liu, W., Sun, L., Kang, H., Yang, H., and Zhang, P.: Iodine speciation in marine aerosols along a 15000-km round-trip cruise path from Shanghai, China, to the Arctic Ocean, Environ. Chem., 7, 406-412, https://doi.org/10.1071/EN10048, 2010.

Xu, S., Freeman, S. P. H. T., Hou, X., Watanabe, A., Yamaguchi, K., and Zhang, L.: Iodine Isotopes in Precipitation: Temporal Responses to ${ }^{129}$ I Emissions from the Fukushima Nuclear Accident, Environ. Sci. Technol., 47, 10851-10859, https://doi.org/10.1021/es401527q, 2013.

Xu, S., Zhang, L., Freeman, S. P. H. T., Hou, X., Shibata, Y., Sanderson, D., Cresswell, A., Doi, T., and Tanaka, A.: Speciation of Radiocesium and Radioiodine in Aerosols from Tsukuba after the Fukushima Nuclear Accident, Environ. Sci. Technol., 49, 10171024, https://doi.org/10.1021/es504431w, 2015.

Zhang, L., Zhou, W. J., Hou, X., Chen, N., Liu, Q., He, C., Fan, Y., Luo, M., Wang, Z., and Fu, Y.: Level and source of ${ }^{129} \mathrm{I}$ of environmental samples in $\mathrm{Xi}$ 'an region, China, Sci. Total Environ., 409, 3780-3788, https://doi.org/10.1016/j.scitotenv.2011.06.007, 2011.

Zhang, L., Hou, X., and Xu, S.: Speciation of ${ }^{127}$ I and ${ }^{129}$ I in atmospheric aerosols at Ris $\emptyset$, Denmark: insight into sources of iodine isotopes and their species transformations, Atmos. Chem. Phys., 16, 1971-1985, 10.5194/acp-16-1971-2016, 2016.

Zhang, L., Hou, X., Li, H., and Xu, X.: A 60-year record of ${ }^{129} \mathrm{I}$ in Taal Lake sediments (Philippines): Influence of human nuclear activities at low latitude region, Chemosphere, 193, 1149-1156, https://doi.org/10.1016/j.chemosphere.2017.11.134, 2018a.

Zhang, L., Hou, X., Fu, Y., Fang, M., and Chen, N.: Determination of ${ }^{129} \mathrm{I}$ in aerosols using pyrolysis and $\mathrm{AgI}-\mathrm{AgCl}$ coprecipitation separation and accelerator mass spectrometry measurements, J. Anal. Atom. Spectrom., 33, 1729-1736, https://doi.org/10.1039/C8JA00248G, 2018b. 